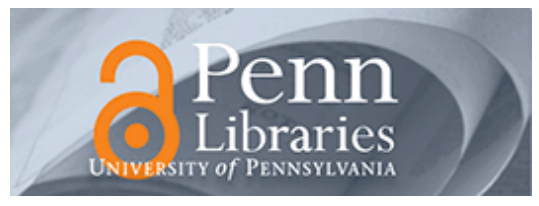

University of Pennsylvania ScholarlyCommons

$11-1995$

\title{
Effects of Horse-Race Coverage on Campaign Coffers: Strategic Contributing in Presidential Primaries
}

Diana C. Mutz

University of Pennsylvania, mutz@sas.upenn.edu

Follow this and additional works at: https://repository.upenn.edu/asc_papers

Part of the Communication Commons

\section{Recommended Citation}

Mutz, D. C. (1995). Effects of Horse-Race Coverage on Campaign Coffers: Strategic Contributing in

Presidential Primaries. The Journal of Politics, 57 (4), 1015-1042. https://doi.org/10.2307/2960400 


\title{
Effects of Horse-Race Coverage on Campaign Coffers: Strategic Contributing in Presidential Primaries
}

\begin{abstract}
The quantity of "horse-race" coverage of political campaigns has been amply documented, but its consequences for the dynamics of campaigns are less well understood. This study examines the effects of media portrayals of public support for candidates on the behavior of potential campaign contributors. This relationship is tested in the context of the four leading Democratic presidential primary candidates in 1988. A time-series analysis of contributor behavior suggests that horse-race spin-that is, the extent of media coverage suggesting a candidate is gaining or losing political support ^helps determine the frequency of campaign contributions. Consistent with previous research, some contributors are motivated to donate by coverage suggesting that their strongly favored candidate is losing ground, while other candidacies benefit from coverage suggesting increased viability. Overall, findings suggest that strategic considerations weigh heavily in decisions to donate money to political candidates.
\end{abstract}

\section{Keywords}

media, campaign contributions, presidential elections

\section{Disciplines}

Communication | Social and Behavioral Sciences 


\title{
Effects of Horse-Race Coverage on Campaign Coffers: Strategic Contributing in Presidential Primaries
}

\author{
Diana C. Mutz \\ University of Wisconsin-Madison
}

\begin{abstract}
The quantity of "horse-race" coverage of political campaigns has been amply documented, but its consequences for the dynamics of campaigns are less well understood. This study examines the effects of media portrayals of public support for candidates on the behavior of potential campaign contributors. This relationship is tested in the context of the four leading Democratic presidential primary candidates in 1988. A time-series analysis of contributor behavior suggests that horse-race spin-that is, the extent of media coverage suggesting a candidate is gaining or losing political support-helps determine the frequency of campaign contributions. Consistent with previous research, some contributors are motivated to donate by coverage suggesting that their strongly favored candidate is losing ground, while other candidacies benefit from coverage suggesting increased viability. Overall, findings suggest that strategic considerations weigh heavily in decisions to donate money to political candidates.
\end{abstract}

bservers of American electoral behavior have long assumed that everyone loves a winner. This principle also has been assumed to apply to the behavior of campaign contributors. In 1932, an analysis of incentives underlying campaign contributions claimed that people "give much as they put money on a winning horse" (Overacker 1932, 190-91). More recent elections abound with claims that perceptions of public support bring with them tangible benefits in the form of financial contributions. This is popularly claimed to have occurred for Carter in 1976, for Anderson in 1980, and for Hart in 1984 (Pomper 1989), although the precise mechanism or dynamics of the proposed effects were never documented.

Horse-race campaign coverage, that is, news emphasizing who is ahead or behind, or gaining or losing ground, is the primary means by which people develop perceptions of the extent of mass public support for candidates. Although the extent of horse-race coverage has been well documented and widely disparaged as a pernicious force in contemporary American politics (see, e.g., Johnston et al. 1990; Brady and Johnston 1987; Broh 1977; Patterson 1980), researchers understand

This research was supported by a grant from the Graduate School of the University of WisconsinMadison and by research assistance from the Freedom Forum Media Studies Center. The author would like to thank Murray Edelman of Voter Research \& Surveys for his contribution to this project.

The Journal OF Politics, Vol. 57, No. 4, November 1995, Pp. 1015-42

C 1995 by the University of Texas Press, P.O. Box 7819, Austin, TX 78713-7819 
little about the concrete consequences it may have for the behavior of the American electorate. In this study I hypothesize that one way in which media portrayals of public support are important in determining the nature of campaigns is through their influence on candidates' abilities to attract contributors and ultimately, to finance a competitive race. Past research has focused on the translation of money into electoral prospects, but little on the precursors or intermediary processes governing electoral outcomes. Since money plays a central role in candidates' abilities to attain office, the dynamics of behavior leading to a healthy campaign war chest are worthy of study.

This study focuses on strategic contributing by primary activists in the 1988 Democratic presidential nomination campaign. Presidential nominations are an ideal setting in which to examine this hypothesis for two reasons. First, the stakes are very high; campaign finance regulations have reduced the importance of money in general elections, but inadvertently have enhanced its role in primaries (Orren 1985). Second, horse-race coverage is most extensive in coverage of the sequential presidential primary races (Arterton 1984; Brady and Johnston 1987). Moreover, by encouraging mass fund-raising efforts aimed at attracting many small donations from large numbers of individuals, ${ }^{1}$ changes in campaign finance regulations have further enhanced the importance of mass media in the process of winnowing presidential aspirants (Traugott 1985).

The 1988 Democratic primary and pre-primary period provides an excellent setting in which to examine effects of changing perceptions of public support. With no clear front-runner, the "seven dwarfs" all needed money and greater visibility to create viable campaigns. Moreover, research on the impact of campaign expenditures on vote choice in presidential primaries suggests that money matters most when there are a large number of low viability candidates (Haynes and Gurian 1992), just as there were at the beginning of the 1988 Democratic primary season.

I begin this examination of strategic contributor behavior by reviewing what is known about motivations underlying decisions to give money to political candidates. Next, I establish the plausibility of strategic contributing by describing two mechanisms by which perceptions of public support might guide people in deciding when and whether to donate. Finally, I specify and test a model predicting the aggregate-level behavior of contributors to the four leading Democratic candidates. Consistent with previous research, the extent and nature of strategic contributor behavior is found to vary with characteristics of candidates' constituencies.

\section{Motivations to CONTRIBUTE}

Contributing to campaigns generally occurs along with other forms of political involvement (Brown, Powell, and Wilcox 1991), but the motives for general

${ }^{1}$ Candidates for the presidential nominations may accept no more than $\$ 1,000$ from any individual contributor and no more than $\$ 5,000$ from any multicandidate committee (see Alexander and Haggerty 1987 for details). Upon qualification for matching funds, only individual contributions are matchable, and only up to $\$ 250$ per contribution. 
political involvement are better understood than those specific to political contributing (Clark and Wilson 1961; Verba and Nie 1972; Heard 1960). Contributing to a campaign typically involves motivations beyond simply wanting to elect a given candidate. Beyond this, the most commonly proposed incentives all share an emphasis on characteristics of the individual, whether it be the person's desire for affiliation, influence, or personal gain.

Although individual predispositions play a necessary role, contributing money is likely to result from an interaction between individual traits and circumstances in the current political environment (Heard 1960). The past emphasis on stable personal traits in explaining decisions to contribute has encouraged research focused on whether people donate at all during a given election cycle rather than what motivates them at the time the actual decision is made. In presidential primaries the timing of these decisions is crucial to a campaign's survival.

Since individuals can give relatively little directly to a primary candidate's campaign, they are unlikely to do so for purposes of some personal favor in return. As Jacobson and Kernell (1983) suggest, individual contributors' motives center more on psychological than tangible rewards. Of the potential psychological rewards, solidary motives are generally believed to be the most important (Brown et al. 1991); people give money out of a desire to maintain social contacts, to gain social recognition, and to avoid social isolation. The conventional wisdom among politicians and pundits echoes this belief:

"The main reason people give to political campaigns is because they don't want to say no to the
person who asked them" (Werth 1988: 38). Brownstein (1987: 46) concurs: "For the most part ...
the forces involved are local, personal; for many ... the decision is not whether to support Bush
over Kemp or Dole .... but whether to reject a direct request from their friend." (Biersack et al.
1992)

Because of the inherent social pressure, face-to-face requests generally are believed to be most effective for raising contributions, with telephone and direct mail lagging behind due to their more impersonal nature.

To the extent that the power of personal influence dominates the process of inducing people to donate, one would not expect media coverage to play much of a direct role in encouraging donations. ${ }^{2}$ As Katz and Lazarsfeld $(1955,185)$ explained in their seminal work, Personal Influence, personal channels can produce considerable social pressure, while media cannot. One might argue that Katz and Lazarsfeld did not have contemporary horse-race coverage in mind, and that they would recognize the potential for similar social pressures to operate through mass media given the current media emphasis on portrayals of public opinion. But when media emphasize the horse race for public support, they generally portray the opinions of diffuse, anonymous, impersonal others-not the close personal acquaintances capable of exerting traditional forms of interpersonal social pressure. To the extent that decisions to contribute are driven either by the normative social

${ }^{2}$ For a discussion of potential indirect effects of horse-race coverage, see Henshel and Johnston 1987. 
pressure of personal solicitation, or by personal traits of individuals, horse-race media coverage should play a negligible role. However, perceptions of public support may affect potential contributors for an entirely different reason-the desire to maximize the impact of their potential contributions.

\section{The Strategic ConTributor}

Popular wisdom aside, what recommends strategic contributing as a likely pattern of behavior among political activists? The direct analogy to strategic voting provides one possible basis for this expectation: contributors may want to avoid wasting their money on a candidate without a chance of winning, just as strategic voters avoid wasting their votes on noncontenders. When potential contributors are ambivalent about whom to support-as is often the case in crowded primary races with difficult-to-differentiate candidates - they may use information about a candidate's prospects to resolve their uncertainty and indecision about whom to support, both financially and otherwise. In one anecdotal example of this phenomenon, a group of contributors attempted to hire Gallup to assess the odds on two candidates before donating (Dionne 1980).

Abramson et al. (1992) estimate that strategic primary voting occurs only around $10 \%$ of the time (cf. Popkin 1991); however, strategic considerations might be expected in greater magnitude among the highly politically involved pool of potential contributors. Simply by virtue of their extraordinarily high levels of political interest and knowledge, this group should be more likely to engage in strategic thinking (e.g., Bartels 1988). Contribution decisions also may be more strategic on the whole than primary vote decisions because of the value of the resource being allocated; potential contributors may be more strategic when they consider the possibility of throwing money - as opposed to single votes - away on a candidate who has little chance of success. By the same token, contributors may enhance the return on their investments by donating to candidates whom they know to be receiving many other donations (see Jacobson and Kernell 1983). Primary activists who intend to vote for a given candidate, but who will not donate money until they are convinced that their candidate has a solid chance of winning, are clearly not the fervent type of advocates that a candidate most desires. Such a contributor probably finds other candidates well within the realm of acceptability as well, and thus is not an ardent or impassioned supporter of his or her chosen candidate. At root, this type of strategic contributor behavior stems from hesitancy and hedging on the part of the primary activist; unless horse-race coverage portrays the candidate as viable, he or she is not willing to make a monetary investment in the candidate's campaign.

Interestingly, one finds precisely the opposite strategic assumption in the literature on direct-mail appeals. Here the operating principle is that contributors are motivated by perceptions of decreasing mass support for their position. As Kayden (1985) notes, "The small donor derives satisfaction-a moral uplift-from 
contributing to a campaign. The issues that provide satisfaction are apt to be issues in which the donor is in the minority. After all, if one is in the majority, why worry?" (95). Many direct-mail appeals include frequent references to the almost certain demise of a campaign unless the recipient donates immediately. Outside the context of direct-mail fund-raising, it is also common for candidates to vie for the "underdog" role for similar reasons (see Adams 1983). The perception that a campaign is embattled and needs help may be an effective fund-raising tactic, particularly in determining the timing of donations. In the face of an imminent threat, loyal supporters of a candidate may be prompted to give money by news that their candidate is threatened or losing ground.

The plausibility of loyalty-based contributing among those strongly committed to a candidate or cause is supported by closely related field and laboratory studies. In fact, many studies of bandwagon phenomena have ended up demonstrating strong underdog patterns rather than movement in the direction of majority opinion (see Marsh 1984 for a review). Movement in the direction of majority opinion occurs mainly when information is low and commitment is weak, while an underdog pattern - whereby people intensify their commitment to a less-popular choiceis more likely when people have high levels of information and well-formed, strongly committed views (e.g., Petty and Cacioppo 1979, 1981; Bartels 1988; Chaiken 1987; Geer 1989; Kaplowitz et al. 1983; Patterson 1980). Studies in this vein generally have focused on changes in attitudes or behavioral intentions rather than actual behaviors. Nonetheless, the mechanism is perhaps even more compelling as a strategic consideration in contributor decisions; if one's chosen candidate is already doing quite well, what need is there to send additional money?

Although information about candidates in a large prenomination field tends to be low, potential contributors - particularly at the primary stage - are likely to be among the most actively involved and well informed (see, e.g., Brown, Hedges, and Powell 1980). These characteristics make loyalty-based contributing all the more plausible; when highly committed voters are faced with information indicating a majority or trend away from their viewpoint, they may stand steadfast, increasing the intensity of commitment to their original views and rallying behind their candidate (see e.g., Fleitas 1971; Gaskell 1974; Ceci and Kain 1982; Mutz 1992; Price 1989).

Loyalty-based and hesitancy-based contributing represent two distinctly different predictions as to the overall pattern of contributing that will transpire. Nonetheless, when people make decisions to contribute that take into account perceived viability - whether for reasons of strong loyalty to a candidate or hesitancy about a candidate's chances-both decision-making processes are highly strategic in nature. In both cases, potential contributors are making a concerted effort to allocate their money more efficiently, either by not giving money to a primary candidate unless they know he or she has a chance of winning, or by not giving money to a candidate until they know he or she truly needs it to win. Conventional political wisdom suggests that both loyalty-based and hesitancy-based strategic contributing 
occur, but there is little, if any, empirical evidence documenting which process is most likely under what conditions.

\section{Characterizing Candidate Constituencies}

One would expect candidates' constituencies to respond differently to changing perceptions of public support based on the nature and intensity of their support for their chosen candidate. The weaker the strength of a constituency's support for a particular candidate, and the less distinguishable that candidate is from other alternatives, the more likely potential contributors will be influenced by hesitancybased strategic considerations; if two or more candidates appear roughly equally attractive, then viability should play a positive role in increasing the frequency of donations. If all other things are perceived to be equal, primary voters will give money to the candidate they think has the better chance.

Loyalty-based contributing should be more likely among candidates whose supporters are strongly committed to their candidacy, and whose candidacy represents an ideological position distinct from that of other candidates in the party. A potential contributor with a strong ideological basis for supporting a candidate would have good reason to respond to news of declining public support: switching to another candidate is a less attractive option because of the intensity of support for the original one, and because the alternatives are likely to be very different ideologically from the preferred choice. These factors should make it more likely that a supporter will rally behind his or her original preference.

What little evidence there is pertaining to the effects of perceptions of mass support on fund-raising is consistent with this pattern. In the 1988 Republican primaries, Mutz (1995) found that donations to Dole and Kemp were positively related to the media-portrayed viability of these campaigns over time, while donations to Bush were not. Thus the also-rans were characterized by hesitancy-based contributing, while the acknowledged front-runner was not, since his viability was never in question. On the other hand, donations to Pat Robertson were negatively related to the media-portrayed viability of his campaign, probably because his highly committed supporters rallied behind him as his prospects began to fade.

Of course, all campaign constituencies include mixtures of different kinds of potential contributors; supporters of a given candidate are never all of one cloth. Nonetheless, it is possible to differentiate candidates and their constituencies based on general tendencies in the pool of potential contributors. To formulate campaignspecific expectations for this study, I gathered information on supporters of the four leading candidates in the 1988 Democratic primary (Dukakis, Jackson, Gore, and Gephardt), including their intensity of commitment to the candidate and their perceptions of these candidates' ideological positions. ${ }^{3}$

${ }^{3}$ The best data bearing on the perceived ideological positions of the candidates comes from the 1988 NES Super Tuesday study. Although the Super Tuesday study is not national in scope and data were collected fairly late in the fund-raising season (January 17 through March 8, 1988), they remain the best source of information on candidates' ideological positions. 
TABLE 1

INTENSITY OF COMmitMent to CHOSEN PRIMARy CANDIDATE

\begin{tabular}{lccc}
\hline & Strongly & Moderately & Only Mildly \\
\hline Gephardt & 23 & 48 & 28 \\
Dukakis & 20 & 46 & 32 \\
Gore & 34 & 44 & 23 \\
Jackson & 71 & 22 & 7 \\
\hline
\end{tabular}

Source: National telephone poll of 1,000 registered voters done by Gordon Black for USA Today, February 23-28, 1988. Percentages represent the proportion of each candidate's supporters who responded as indicated to this question: "How strongly do you favor (chosen candidate) for the 1988 Democratic presidential nomination? Strongly, moderately, or only mildly?”

Table 1 confirms popular impressions that Jackson had an intensely loyal following $^{4}$; only Jackson had an identifiable constituency "whose support he could count on through thick and thin" (Cook 1989, 46). Although there is a large gap between Jackson and the other three candidates, Gore's supporters were also surprisingly strongly committed to his candidacy, with more than a 10-point gap between the percentage of his supporters who were strongly committed, and those equally committed to either of the remaining two candidates.

The likelihood that a candidate's supporters will take viability into consideration when making decisions about donating also should be a function of the ideological distinctiveness of the candidate in the eyes of his supporters. Table 2 illustrates just how distinctive each group of supporters perceived their respective candidate. Not surprisingly, these groups had very different general perspectives on the candidates' positions. For example, Jackson supporters perceived the entire field of candidates to be particularly conservative, while Gore supporters perceived them to be particularly liberal. Jackson supporters also discriminated fewer ideological differences among the candidates, with a range from lowest to highest of only threequarters of a point on a seven-point scale, whereas Gore supporters used almost a full two-point range in ranking the same candidates.

For purposes of characterizing constituencies by the extent to which they see their candidate as ideologically distinct, what is of interest is within-group differences in ideological attributions, ignoring differences in each constituency's use of the ideology scales. The normalized distance scores shown in the third column of table 2 make it possible to compare perceived ideological distinctions across the four groups of candidate supporters. As shown by the boldface lines in table 2, perceived candidate ideological positions demonstrate a pattern similar to that for intensity of commitment. Of the four major candidates, Jackson and Gore were the most ideologically distinct, with distances of 1.19 and .94 to the nearest alternative

\footnotetext{
${ }^{4}$ These data were selected because they represent the earliest available assessment of the intensity of supporters' commitment to their chosen candidates, and thus are the most applicable to the fundraising period studied here.
} 
TABLE 2

Perceived Ideological Positions by Supporters of Major Candidates

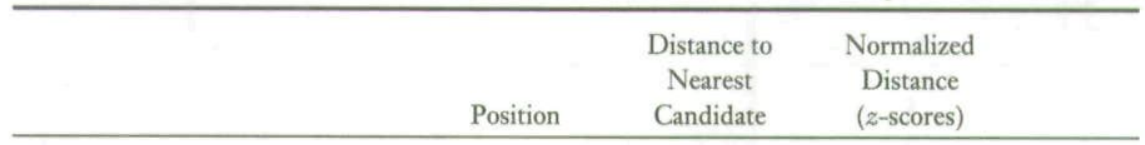

Among Gephardt Supporters $(n=189$, range $=1.30)$

$\begin{array}{lllr}\text { Gephardt } & 4.06 & .25 & .00 \\ \text { Dukakis } & 3.58 & .23 & -.71 \\ \text { Gore } & 3.81 & .23 & -.71 \\ \text { Jackson } & 3.05 & .29 & 1.41\end{array}$

Among Dukakis Supporters $(n=268$, range $=1.16)$

$\begin{array}{lllr}\text { Gephardt } & 3.54 & .26 & 1.20 \\ \text { Dukakis } & 3.80 & .07 & -.82 \\ \text { Gore } & 3.87 & .07 & -.82 \\ \text { Jackson } & 2.90 & .19 & .45\end{array}$

Among Gore Supporters $(n=153$, range $=1.82)$

$\begin{array}{lllr}\text { Gephardt } & 3.78 & .46 & .24 \\ \text { Dukakis } & 3.32 & .46 & .24 \\ \text { Gore } & 4.32 & .54 & .94 \\ \text { Jackson } & 2.77 & .27 & -1.42\end{array}$

Among Jackson Supporters $(n=211$, range $=.72)$

$\begin{array}{lllr}\text { Gephardt } & 3.80 & .10 & .46 \\ \text { Dukakis } & 3.90 & .03 & -.83 \\ \text { Gore } & 3.93 & .03 & -.83 \\ \text { Jackson } & 3.66 & .14 & 1.19\end{array}$

Source: 1988 NES Super Tuesday Study. Data are based on the major Democratic candidates, defined as those whose percentage support reached double digits. The first column represents the mean ideological placement of the candidate in the first panel; higher scores indicate the candidate is perceived as more conservative. The second column represents the distance from the candidate placement to the nearest alternative Democratic candidate within that group of supporters; the third column consists of normalized distance scores that can be compared across different groups of supporters.

candidates. Gephardt and Dukakis, on the other hand, were perceived by their respective supporters to be less ideologically distinct, with distances of .00 and -.82 to the nearest alternative candidate. ${ }^{5}$

These data generally confirm Cook's (1989) assertions about the nature of the various campaigns: Jackson's supporters were strongly committed to his particular candidacy; Gore was successful in differentiating himself from the pack of Democratic contenders and attracting supporters on the basis of his stance as the more conservative and hawkish candidate: "Other Democratic candidates were on a basically similar wavelength. Only Gore-and then only occasionally-used the

${ }^{5}$ This logic assumes as its point of departure that ideology plays some role in influencing voter preferences in primaries (see, e.g., Lengle 1981; Polsby 1983). 
numerous debates to draw a sharp distinction between himself and the other candidates on the issues" (Cook 1989, 47). In contrast, Dukakis and Gephardt's campaigns emphasized nonideological appeals such as managerial skills, leadership, energy, and independence.

In a sense, all of the "seven dwarfs" in 1988 were also-rans whose campaigns potentially could be influenced by strategic contributor behavior. Variations in the intensity of constituent support suggest that the constituencies supporting candidates Dukakis and Gephardt were especially likely to exhibit signs of hesitancybased strategic contributing given the lack of robust support that predominated among their constituencies, and the lack of distinctiveness in their perceived ideological positions. The strong commitment and ideological distinctiveness of Jackson's supporters made his candidacy the most likely to exhibit signs of loyaltybased contributing. The pattern suggested by Gore's supporters more closely resembles the pattern of Jackson's supporters than the patterns of either of the other two candidates. Although the pattern is less clear for him, it suggests that, if anything, his campaign war chest should have been more susceptible to loyaltybased contributing than hesitancy-based considerations.

\section{STUDY DESIGN}

To document strategic contributing of either the loyalty-based or hesitancydriven variety, it is necessary to eliminate other, nonstrategic reasons that changes in perceptions of public support might lead to changes in the flow of donations received by a campaign. As in studies of strategic voting, strategic motivations to contribute are established indirectly by ruling out plausible alternatives. Figure 1 illustrates three potential mechanisms by which perceptions of public support for a candidate could influence the aggregate number of campaign contributions a candidate receives at a given point in time. The broken lines represent two paths to increased donations that are extensions of two varieties of momentum. In both cases, the number of contributions is indirectly increased by expanding the size of a candidate's base of voter support. For example, as the diagonal broken line indicates, to the extent that strategic voting increases a candidate's base of voter support, it may thereby increase the flow of donations. Although one might assume that all of a primary candidate's potential contributors would be those who supported him from the very beginning, strategic voters are among the most well-informed and politically active primary voters, thus making them likely campaign contributors if they do, in fact, shift to another candidate's camp. Moreover, the long pre-primary season replete with straw polls, endorsements, and local, regional, and national polls means that even very early supporters may take strategic considerations into account.

The path formed by the vertical and horizontal broken lines in figure 1 represents forms of momentum that are mediated by attitude change. To the extent that perceptions of candidate support alter attitudes toward candidates (see Bartels 


\section{FIGURE 1}

The Potential Influence of Perceptions of Public Support ON POLITICAL CONTRIBUtions

(AgGregate-Level Model)

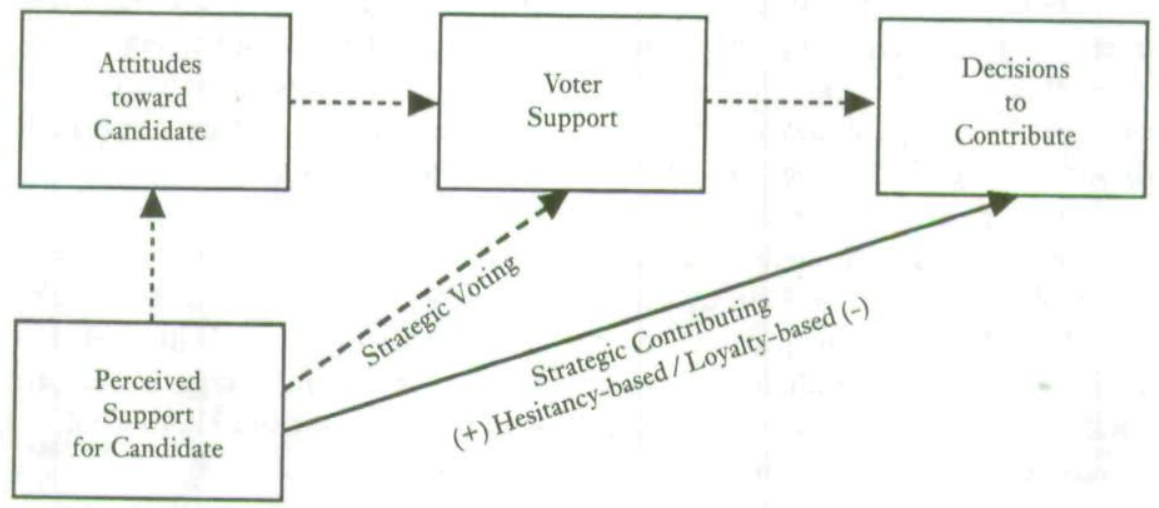

Dashed lines represent forms of momentum that are mediated by changes in attitudes toward candidates. Paths that do not deal with the translation of perceived public support into contributions have been omitted. (For example, attitudes toward candidates will also influence perceptions of public support, and decisions to contribute are likely to intensify subsequent attitudes toward candidates.)

1988 for details), they may also increase the base of voter support which, in turn, facilitates increased donations. Given the activist nature of political contributors, and the fact that these types of momentum tend to characterize less-informed primary voters, this path is less likely to play an important role in altering contributor behavior.

In this study I focus specifically on the relationship in figure 1 that has not been examined in previous work; that is, the effect that perceived support for candidates has on decisions to contribute that are not a result of changes in the size of a candidate's constituency. ${ }^{6} \mathrm{I}$ use the term "strategic contributing" to refer to situations in which perceptions of public support alter the flow of contributions directly, not by changing people's attitudes toward candidates, nor by changing their preferred candidate. Instead, media coverage of the horse race simply alters people's perceptions of an already-liked candidate's chances of victory, and thus facilitates strategic contributions. By explicitly controlling for changes in the size of candidates' constituencies, I will eliminate the possibility that these other processes are responsible for relationships between changes in perceived public support and the flow of donations.

${ }^{6}$ The indirect paths that could result in increased donations have been analyzed in Bartels's (1988) study of momentum. 


\section{DATA AND MEASURES}

The dependent variables used in this study were constructed from information on contributions to primary candidates available from the Federal Election Commission (FEC). The FEC mandates that records be kept for all donations of two hundred dollars or more. Instead of relying on cumulative data, I used records on individual donations received by each candidate based on the date he was recorded at campaign headquarters. These data were aggregated by week to form measures of the number of donations from private individuals each candidate received each week. ${ }^{7}$ Only contributions received by the candidate's principal campaign committee or another authorized campaign committee were counted toward this total. ${ }^{8}$

Breaking down FEC data in this fashion makes it possible to use continuous over-time variance in the flow of contributions as opposed to variance by candidate, type of race, or year, as is most often the case. Nonetheless, since they are aggregate data, they retain all of the requisite limitations in drawing inferences about individual motives and behaviors (e.g., Robinson 1950).

Since I am primarily interested in the processes underlying individual decisions to donate, I used the number rather than the monetary total of donations received each week. Cumulative amounts are clearly important, but the amount of a given donation is more likely to be influenced by idiosyncratic factors such as personal affluence, while the total number of donations should be more evenly influenced by external factors.

In studying contributor behavior, it is important to begin a time series well before the primary season itself; the "exhibition" season is a crucial time during which candidates must scramble to raise seed money if the campaign is to continue (Orren 1985). Moreover, media are probably most influential in shaping public perceptions of support for candidates when there are no actual primaries to guide perceptions. In light of these considerations, I gathered data spanning a 42 -week period from July 1, 1987, through the date when the candidate was no longer in the race. ${ }^{9}$

\section{Horse-Race Spin}

Since media-conveyed information about likely winners and losers is easily absorbed and recalled by the public (e.g., Robinson and Clancey 1985), perceptions

\footnotetext{
${ }^{7}$ This study includes transaction types 15 and $15 \mathrm{E}$. Candidates' contributions to their own campaigns (transaction type 15C) are excluded from this analysis.

${ }^{8}$ To circumvent FEC limits, many candidates fund their preannouncement activities through candidate PACs rather than authorized campaign organizations. Although these organizations play a major role in the preannouncement stage when individual donations to candidates cannot yet be matched, they are a minor factor during the time period of interest here. Moreover, including donations to candidate PACs in these totals did not change the nature of the relationships reported in this study.

${ }^{9}$ The race was resolved during the same week for Dukakis, Gore, and Jackson; thus they have the same number of weeks' worth of data. However, Gephardt dropped out three weeks earlier, thus
} 
of public support for candidates were tapped by assessing horse-race coverage pertaining to each candidate's chances. ${ }^{10}$ The major television networks and nationally oriented newspapers generally agree in their assessments of candidates' performance and prospects (Marshall 1983); thus it is safe to assume that newspaper readers and television viewers receive essentially the same representation of the primary race. Since the AP wire service crosses over both print and broadcast media, it serves as an appropriate source to measure the "spin" on horse-race coverage surrounding individual candidacies. Media representations of candidate support were gauged using a computer-assisted content analysis of a random sample of AP wire-service stories. For each candidate, one thousand stories were randomly selected from the total pool of stories mentioning the candidate's name. ${ }^{11}$

A computer-aided content analysis assessed the spin regarding whether the candidate was portrayed as winning or losing, gaining or losing ground according to each paragraph (see Fan 1988; Nacos et al. 1991). The rules used to code the content took into account word and phrase combinations, the distance between words, the order in which words appeared, and the presence of negatives or other concepts in the paragraph. For example, in an analysis of Dukakis stories, "Dukakis ... outscored ... Jackson" would be recognized as positive spin for Dukakis, while "Jackson ... outscored ... Dukakis" would be scored as negative spin for Dukakis. Similarly "Dukakis ... outscored . . . by ... Jackson" would be recognized as negative spin for Dukakis. ${ }^{12}$ To create a composite measure indicating the amount of positive spin relative to negative spin for each candidate, I constructed a weekly ratio of the number of positive to negative spin news stories. ${ }^{13}$

providing three fewer data points for the analysis of his campaign. The sample size of 1,000 stories per candidate was reduced proportionately $(n=929)$.

${ }^{10}$ Candidates' successes in primaries and caucuses typically have been lumped together with coverage of them as if they were a single entity. Bartels (1988), for example, weights his measure of each candidate's cumulative primary vote share by the amount of coverage the subsequent week. Aldrich (1980) examines actual and expected performances specifically in publicized primaries. While there is nothing inherently wrong with this practice, it does little to help disentangle the primary-driven and mediadriven components of this process, and it limits knowledge of the influence of perceived support to the relatively short primary season.

"The precise specification for the universe of stories from which each separate candidate sample was drawn was any story including the candidate's first and last name (see footnote 9).

${ }^{12}$ Coder attempts to differentiate references to whether candidates were ahead versus gaining ground or behind versus losing ground proved impossible since most coverage seemed to blend the two, even within single sentences. Coders aside, people in general apparently have a difficult time differentiating state from trend information (Jencks 1991), thus suggesting that those consuming these media stories will not differentiate either.

${ }^{13}$ For example, a positive (negative) spin story was defined as one which contained one or more paragraphs of positive (negative) spin. For more specific details on coding, please contact the author for the complete list of rules. To assess the reliability of this procedure, a random subsample of 250 paragraphs from the 1,000 stories for each candidate was coded by an independent human coder whose scores were then compared to those generated by the computer program. This process resulted in approximately $85 \%$ of paragraphs classified correctly across the four candidates. Most errors were Type II errors; that 


\section{Primary Outcomes}

Indicators also were constructed to represent ongoing primary victories that could directly influence public perceptions of the candidates' chances. Measures of a candidate's "objective" probability of nomination were constructed from a ratio of each candidate's cumulative delegates to date relative to the total number needed to secure the nomination. ${ }^{14} \mathrm{~A}$ second indicator comprised the share of the primary vote the candidate had won in the most recent primary. As Bartels (1988) argues, public perceptions "respond with special force, at any given point in the campaign, to the most recent primary results" (324). The candidate's cumulative percentage of the primary vote to date served as a third indicator of accumulating support. Although each of these three measures taps slightly different aspects of ongoing primary events and their meaning, preliminary analyses indicated that they were highly intercorrelated $(\bar{r}=.74)$. To avoid multicollinearity problems in further analyses, they were normalized and combined into a single additive index representing primary outcomes.

\section{The Campaign War Chest}

Very few contributions are truly spontaneous; to receive contributions, most candidates must ask. Their ability to make mass fund-raising appeals through direct mail or broadcast advertising may, in turn, be constrained by the size of their campaign war chests. Ideally a model of contributor behavior would take into account the amount of money the campaign is spending on advertising, direct mail, or other fund-raising appeals. Unfortunately, it is not feasible to compile precise data on the amount of money spent on fund-raising on a week-by-week basis (see McBurnett 1991). But if one assumes that the percentage of the campaign budget spent on such activities is fairly consistent across candidates, then the size of the war chest itself can serve as a surrogate for fund-raising expenditures. ${ }^{15}$ Cook (1989) reports that in 1988, candidates all adopted basically the same strategy, starting early and focusing their energies on fund-raising during the exhibition season. Although this assumption may be tenuous at best, it allows some accounting for the vast differences in initial availability of resources.

\footnotetext{
is, they resulted from not scoring paragraphs that did involve horse-race considerations rather than inappropriately coding coverage that did.

${ }^{14}$ Sources for this information included Congressional Quarterly Weekly Reports and the ABC News Bureau primary reports. Inconsistencies were resolved in favor of the more exhaustive source of information on primaries and caucuses, the $\mathrm{ABC}$ News Bureau. Since these ratios are equal to zero before the beginning of the primary season, these indicators are constant for all candidates during this period.

${ }^{15}$ This measure is the cumulative amount of money raised for the campaign since 1986 from individuals as well as political-action committees. For ease of interpretation, these figures are expressed in hundreds of thousands. To the extent that personal solicitations are responsible for the bulk of contributions, fund-raising expenditures would not serve as a reliable measure of the amount of "asking" taking place.
} 


\section{Amount of Media Coverage}

Bartels (1988) suggests that momentum may occur because people "respond quite unthinkingly to changes in simple political stimuli such as the frequency with which candidates' names appear on television and in the newspaper" (111). Still other research suggests that to the extent that simple amount of coverage plays a significant role, it is often a negative one; surges in coverage that are not about a candidate's success or failure in attracting public support often result from scandals or faux pas (e.g., Hagen 1992). To incorporate these possibilities, the same samples of media content described earlier were used to construct indicators of the amount of media coverage received by the candidates over time by summing the number of paragraphs mentioning each candidate each week. Since the original one thousand stories per candidate are each random samples, all stories dealing with the candidate that appeared during the study time frame should accurately reflect increases and decreases in coverage of each candidate over time.

\section{Voter Support}

Indicators of vote choice were gathered from national polls conducted throughout the study period. The percentage of a candidate's support was drawn only from polls that asked such questions of appropriate nationwide party subsamples. ${ }^{16}$ These measures were included in the model to ensure that the ebb and flow of contributions did not result from momentum simply enlarging the pool of voters supporting a particular candidate.

\section{SPECIFYING A MODEL}

Unfortunately there are no extant theories of contributor behavior to guide construction of an explanatory model (Jones and Miller 1985). Interestingly, the numbers of contributions to the 1988 Republican candidates were found to be positively related to one another over time, thus suggesting that increases in donations to one candidate did not drive donations to others down as one might have expected (Mutz 1995). Instead, the same general over-time trends seemed to influence all candidates at any given point in time.

A preliminary examination of the dependent variables in this study confirms that there are strong "seasonal" influences on political giving. Figure 2 shows that the peaks and valleys in the number of contributions different candidates received

\footnotetext{
${ }^{16}$ Each candidate's competitive advantage in poll standings was calculated for each time point by computing the average amount of support for all candidates using that particular version of the question, and then calculating the percentage point advantage to the individual candidate. Polls were obtained from the Roper Archive's Public Opinion Location Library. When more than one poll was done in a particular week, the average was used. When no new suitable polling data were gathered in a particular week, the previous week's indicator was used. Fresh data were available for all but seven of the weeks covered in the time series.
} 
FIGURE 2

\section{NUMBER OF DONATIONS TO FOUR LEADING \\ Democratic Candidates by WeEk}

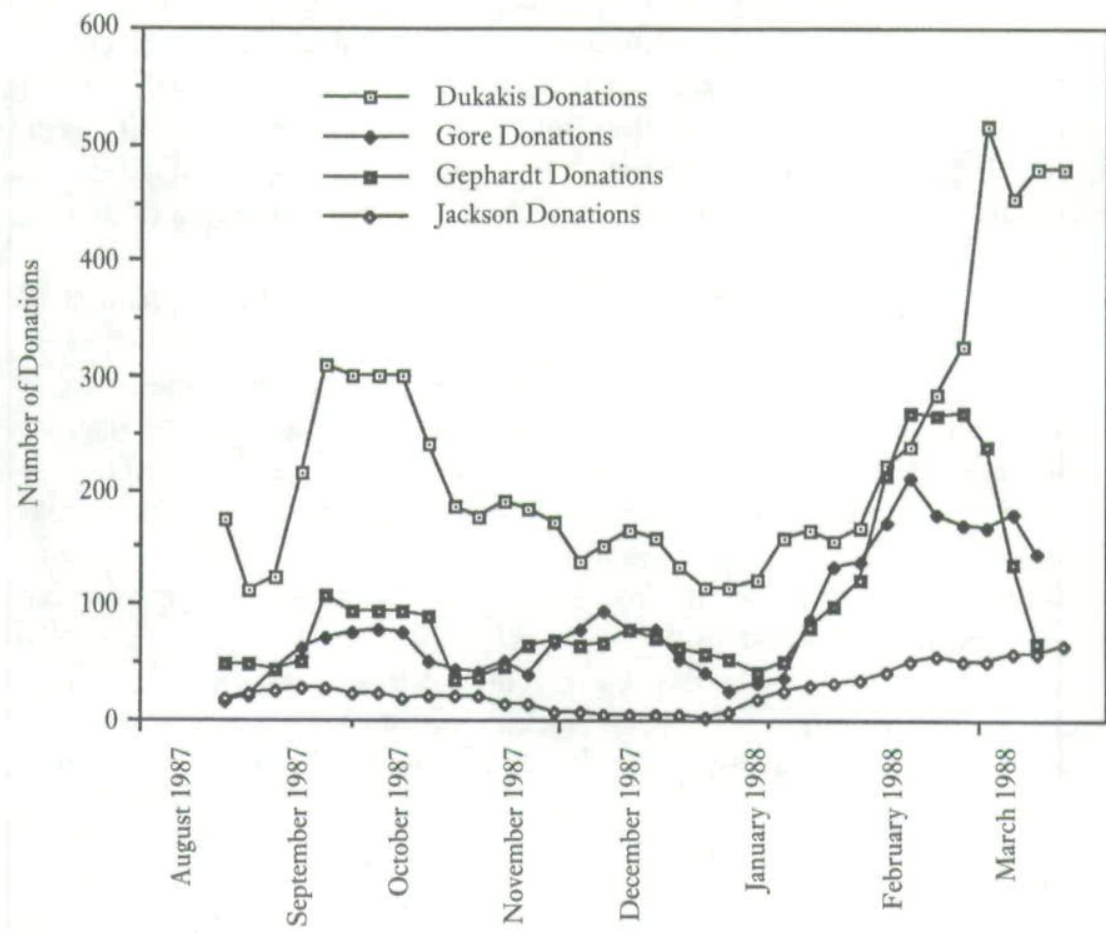

generally occurred together. Increased donations for Dukakis, for example, do not appear to drive contributions to the other candidates down. Instead, forces outside of the individual campaigns - perhaps media attention to the campaign in general or factors tied to family cash flow-appear to drive the general pattern of donations over time.

To take these fluctuations into account, regression equations predicting the number of donations to each candidate controlled for the average number of donations received by the other primary candidates that particular week. My goal in taking into account increases and decreases that affect all candidates is to eliminate the shared over-time variance due to seasonal factors; an increase in the number of donations a candidate receives from one week to the next is only meaningful to the extent that it is greater than the increase that would be expected due to factors influencing all candidates. Thus, the remaining variance represents each candidate's competitive advantage in individual fund-raising relative to the fund-raising successes enjoyed by his opponents at the same point in time. 
Ideally it would be possible to identify lag structures for each independent variable and then isolate the exact time of the contributor decision in relation to them. However, the lack of theory and previous research bearing on these relationships makes this approach impractical. Instead I constructed a very general model designed to incorporate lags appropriate to a range of fund-raising techniques.

Keeping in mind that donations are dated according to when they are received at campaign headquarters, and that much fund-raising occurs through the mail, it seems unlikely that a pronounced effect from a change in perceived viability would be visible in as short a period as a week. This suggests a minimal lag of at least two weeks before one could expect the result of changes in horse-race spin to show up in checks at headquarters.

According to direct-mail experts, almost all of the responses to a request for money will be returned within three to four weeks of the original request (approximately five weeks after the initial mailing), or not at all. Combining these two observations, and taking into account the fact that the checks must then be logged in at headquarters, the time frame in which one could safely expect a contributor response to be registered in these data would be in the range of two to five weeks. Thus, the independent variables described earlier were lagged to create measures representing the average amount of media spin, size of war chest, amount of coverage, etc., during the period two to five weeks before the week donations were recorded at campaign headquarters. Using rolling averages makes it difficult to estimate decay rates or points of peak influence, but it allows for the fact that different, yet simultaneous methods of collecting donations would function at somewhat different lags. ${ }^{17}$

\section{RESULTS}

As might be expected, autocorrelation of the error terms necessitated a two-step full transform (EGLS) method to take into account first-order autoregressive processes $^{18}$ (see Judge et al. 1980 or Harvey 1981 for details). This procedure resulted in Durbin-Watson statistics within acceptable ranges for all four candidates (see Johnston 1972).

${ }^{17}$ Using Dukakis as an example, the hypothesized relationships are described by the equation:

$$
y_{t(D)}=a+b_{1} \mathbf{x}_{1(t-q)}+b_{2} \mathbf{x}_{2(t-q)}+b_{3} \mathbf{x}_{3(t-q)}+b_{4} \mathbf{x}_{4(t-q)}+b_{5} \mathbf{x}_{5(t-q)}+b_{6} \mathbf{x}_{6(t)}+e
$$

where $y_{t(D)}=$ the number of donations received by candidate Dukakis at week $t$

$q=$ the proposed time lag of two to five weeks

$a=\mathrm{a}$ constant

$\mathrm{x}_{1(t-q)}=$ the ratio of positive to negative media spin two to five weeks prior

$\mathrm{x}_{2(t-q)}=$ the index of objective probability of nomination two to five weeks prior

$\mathrm{x}_{3(t-y)}=$ the total amount of coverage the candidate received two to five weeks prior

$\mathrm{x}_{4(t-q)}=$ the size of the candidate's campaign war chest two to five weeks prior

$\mathbf{x}_{5(t-q)}=$ the amount of voter support two to five weeks prior

$\mathrm{x}_{6(t)}=$ the average number of donations received by all candidates at week $t$

${ }^{18}$ Durbin-Watson statistics were 2.19, 2.26, 1.49, and 1.47 for Gore, Gephardt, Dukakis, and Jackson, respectively. 
TABLE 3

PREDictors of DONATIONS to CaMPaignS WITH WEAK CONSTITUENCY SUPPORT

\begin{tabular}{|c|c|c|c|}
\hline \multicolumn{4}{|c|}{ Gephardt Campaign } \\
\hline & & Coefficient & $T$-ratio \\
\hline & Intercept & 46.15 & .64 \\
\hline & Gephardt horse-race spin & 98.23 & 2.73 \\
\hline & Gephardt voter support & 41.20 & 3.00 \\
\hline & Primary outcomes & 96.26 & 1.81 \\
\hline & Amount of media coverage & -1.16 & 1.72 \\
\hline & Size of war chest & 9.10 & 1.54 \\
\hline & All-candidate trend & .43 & 2.03 \\
\hline & \multicolumn{2}{|l|}{ Total $R^{2}$} & .64 \\
\hline \multicolumn{4}{|c|}{ Dukakis Campaign } \\
\hline & & Coefficient & $T$-ratio \\
\hline & Intercept & 156.94 & .94 \\
\hline & Dukakis horse race-spin & 121.66 & 1.81 \\
\hline & Dukakis voter support & 58.51 & 3.16 \\
\hline & Primary outcomes & -40.42 & .18 \\
\hline & Amount of media coverage & -1.93 & 1.40 \\
\hline & Size of war chest & 8.81 & 2.90 \\
\hline & All-candidate trend & 2.36 & 8.73 \\
\hline & Total $R^{2}$ & & .76 \\
\hline
\end{tabular}

Note: Coefficients are iterated Yule-Walker estimates. Dependent variable is the number of donations to a candidate-authorized campaign committee. Gephardt $N=39$, Dukakis $N=42 . R^{2}$ represents the measure of fit of the structural part of the model after transforming for the autocorrelation.

As indicated in table 3, the dynamics of donations to the Gephardt and Dukakis campaigns were similar in many respects. The frequency of donations to both campaigns was partly a function of an increased pool of voters. Both were able to boost the number of donations their campaigns received by bringing more voters into the fold. The size of the coefficients corresponding to voter support suggests that each percentage point advantage that Dukakis accrued over his competitors resulted in slightly less than 60 additional donations, while Gephardt gained slightly more than 40 donations for a similar increase in his voter support. Dukakis also clearly benefited from his early fund-raising successes. The size of his war chest facilitated still more successful fund-raising efforts later in the primary season.

The horse-race spin presented in coverage of their campaigns had similar significant effects, although the coefficient is marginally significant in Dukakis's case $(p<.10)$. For Dukakis, the size of the coefficient corresponding to horse-race spin suggests that in a week of media coverage with twice as much positive as negative spin, the Dukakis campaign could expect roughly 120 more donations relative 
FIGURE 3

\section{RELATIONSHIP BETWEEN NUMBER OF DONATIONS TO GEPHARDT AND GEPHARDT MEDIA SPIN}

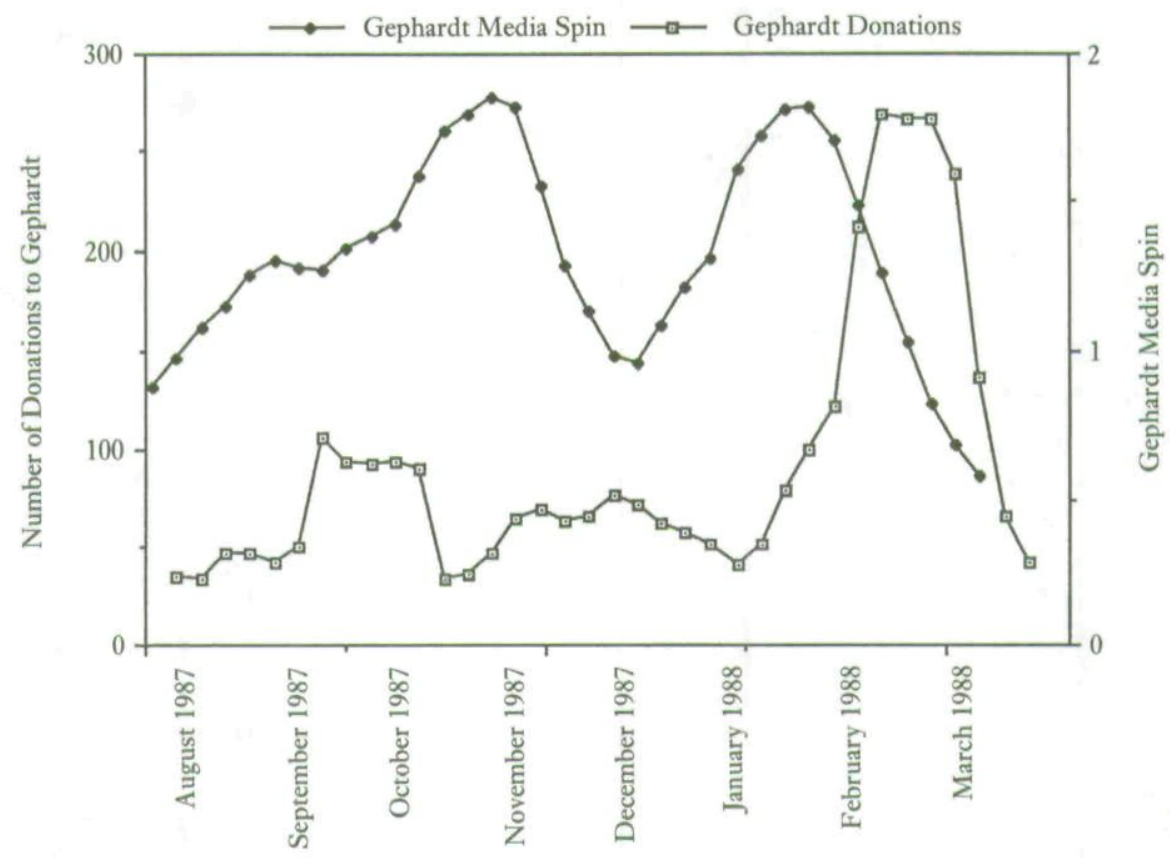

to what would be expected with coverage balancing positive and negative spin. For Gephardt, the coefficient for media spin is clearly significant, but slightly smaller, suggesting around one hundred additional donations. The overall fit for the regression equations is fairly strong in both cases, with $R^{2}$ 's in the $60 \mathrm{~s}$ and $70 \mathrm{~s}$. In general, then, the campaigns with weak constituency support demonstrated the predicted pattern of response to perceived candidate viability; supporters hedged their bets when the campaigns did not appear to be faring well and donated more often when the candidate's popularity was perceived to be on the upswing.

Figure 3 and figure 4 illustrate the simple bivariate relationships between media spin and the number of donations to the Gephardt and Dukakis campaigns, respectively. In figure 3, the three peaks in contributions to Gephardt are each preceded by peaks in media spin. The positive spin forming a minor peak in late August corresponds closely to the timing of a straw poll announced August 30 showing Gephardt running first in Iowa. This is followed by a similar peak in donations at approximately one month's lag. The second and largest peak in horserace spin is followed by a modest surge in contributions, again at approximately one month's lag from peak to peak and valley to valley. The sharp dip in horse-race 
FIGURE 4

\section{RELATIONSHIP BETWEEN NUMBER OF DONATIONS TO DUKAKIS AND DUKaKIS MEDIA SPIN}

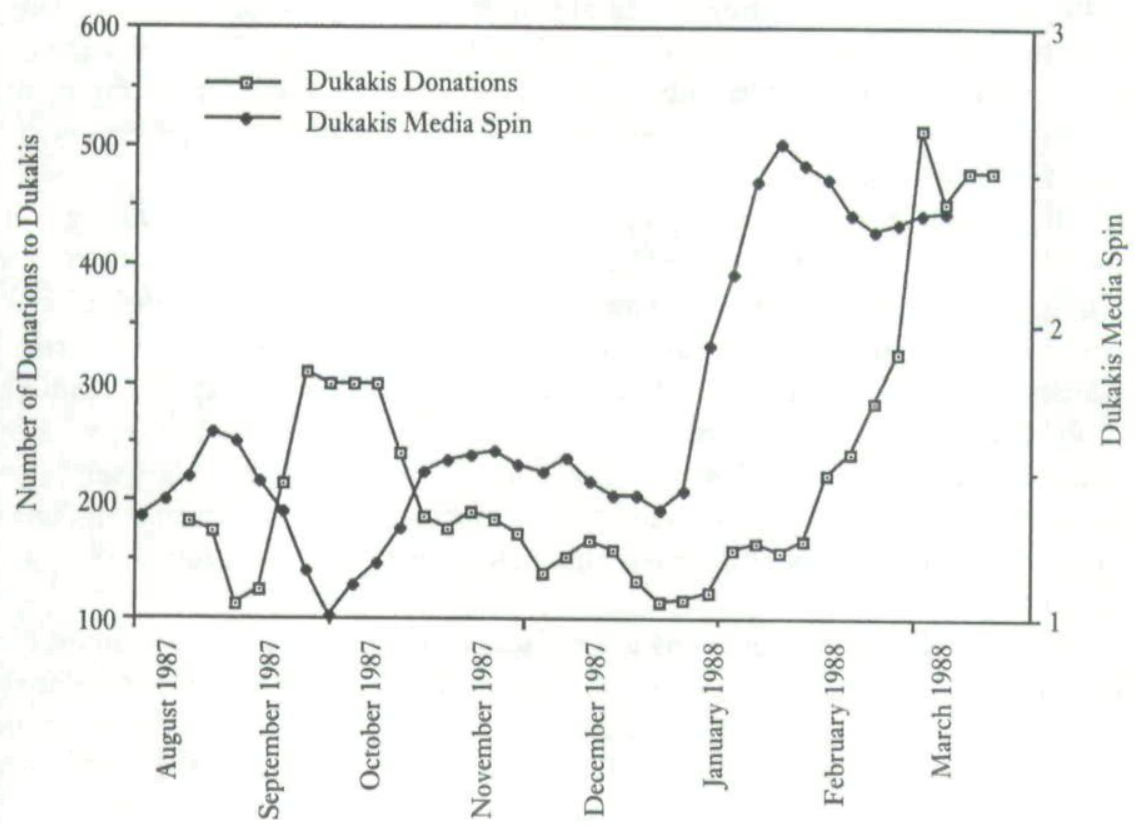

spin in November closely corresponds to the release of a Des Moines Register poll showing Gephardt losing ground to the other candidates in Iowa. The third peak in positive media spin occurred in January and was almost as high as the earlier peak. It also was followed roughly one month later by several consecutive weeks in which Gephardt attracted more than 250 donations.

In figure 4, the two major peaks in donations to Dukakis-in September 1987 and late February 1988-are also preceded roughly one month before by the two most-pronounced peaks in media spin. In August 1987, optimism abounded, but a series of mishaps in September apparently brought down the positive media spin surrounding his campaign. In early September a financial disclosure report showed that Dukakis had held stock in companies doing business in South Africa until the previous year, even though he had signed legislation divesting state pension funds from firms with South African ties in $1983 .{ }^{19}$ On September 20, the Boston Herald reported that Dukakis was in violation of campaign finance regulations. At the end of that same month, Dukakis's campaign director resigned after

${ }^{19}$ The time lines for major campaign events for Dukakis and for the other three candidates were obtained from "CBS News Campaign '88 Primaries and Caucuses, Book 2," which covers the entire time period included in this study. 
admitting that he distributed a video maligning Biden to news organizations. The effects of declining spin in September are clearly visible in the drop-off in donations in October.

Dukakis media spin bounced back in October and November as he won the New Hampshire caucuses and came in second in a series of CBS/Nem York Times polls, both nationally and in Iowa, and first in a New Hampshire poll. The campaign remained buoyed through December as he accumulated endorsements from many mayors and city council members, and was dubbed one of the top six governors and "the leader of the innovation pack" by U.S. Nems and World Report.

The highest peak in Dukakis media spin was in January 1988. During this month a poll of New Hampshire Democrats conducted by Gallup for the Boston Globe showed him retaining his wide lead; moreover, a Des Moines Register poll later in the month showed Dukakis in a three-way tie among Iowa caucus participants. This peak in positive spin dropped off and then leveled out at the beginning of February when Dukakis came in third in the Iowa caucuses, just as the peak in donations in late February dropped off and leveled out in early March. Even some of the more minor peaks in Dukakis spin are mirrored by small increases in donations from October through January, although the pattern is less pronounced during this period.

As table 4 illustrates, donations to the Jackson and Gore campaigns followed a far different pattern. As hypothesized, horse-race spin was a significant negative predictor of donations for both candidates. However, the size of the coefficients in table 4 indicates that these negative effects were of a much smaller magnitude than the positive effects observed for Dukakis and Gephardt. Jackson and Gore gained only around 20 or 30 additional donations from having their campaigns portrayed as threatened or losing ground, while Gephardt and Dukakis gained nearly one hundred or more donations in response to equivalent shifts in horse-race spin. Although there is some evidence corroborating the idea that strongly supportive constituencies rally behind their candidates in times of need, the strength of this strategic pattern pales in comparison with that of candidates with weak constituency support. The amount of media coverage also had a significant impact on donations for both candidates, but as in previous studies, results were mixed: amount of coverage was negatively related to Jackson donations but positively related to Gore donations.

The overall fit for the Jackson equation is not nearly as good as for the other candidates $\left(R^{2}=.48\right)$. The weakness of this model may result from several causes. Research on the 1984 primaries has suggested that the media treated Jackson's candidacy fundamentally differently from other candidates (see Broh 1987), and the same may well have occurred in 1988. The weakness of the Jackson model might also result from the fact that many of Jackson's supporters were outside of the Democratic party's traditional financial base and thus may have been motivated by different considerations. A still more likely explanation is that the FEC data are a less accurate reflection of the total number of donations Jackson received than they 
TABLE 4

Predictors of Donations to CampaignS WITH STRONG CONSTITUENCY SUPPORT

\begin{tabular}{lcc}
\hline & Gore Campaign & \\
& Coefficient & $T$-ratio \\
\hline Intercept & -46.93 & .97 \\
Gore horse-race spin & -28.28 & 2.85 \\
Gore voter support & 13.07 & 1.61 \\
Primary outcomes & -88.61 & 2.92 \\
Amount of media coverage & 1.00 & 2.27 \\
Size of war chest & 6.41 & 1.75 \\
All-candidate trend & .18 & 1.44 \\
Total $R^{2}$ & & .67 \\
& & \\
& Jackson Campaign & $T$-ratio \\
\hline Intercept & Coefficient & 2.13 \\
Jackson horse-race spin & 68.70 & 2.54 \\
Jackson voter support & -19.99 & 1.56 \\
Primary outcomes & 3.22 & 3.20 \\
Amount of media coverage & 76.02 & 2.33 \\
Size of war chest & -.41 & 1.60 \\
All-candidate trend & 8.49 & 1.08 \\
Total $R^{2}$ & .03 & .48 \\
\hline
\end{tabular}

Note: Coefficients are iterated Yule-Walker estimates. Dependent variable is the number of donations to a candidate-authorized campaign committee. $N=42 . R^{2}$ represents the measure of fit of the structural part of the model after transforming for the autocorrelation.

are for other candidates. Jackson's campaign probably attracted a greater number of smaller donors that the FEC records do not take into account. ${ }^{20}$

In figure 5 one can see the inverse relationship between media spin and Gore contributions very clearly. The peak in media spin in early August is followed by a dip in contributions a few weeks later. The decreasing positive media spin Gore received in late September is followed by increased contributions in early October. And so the pattern continues in figure 5, with the peaks and dips in donations always slightly to the right of the opposing peaks and dips in media spin. Gore received his most positive media spin in January 1988 while he was picking up key endorsements, but this plunged to pessimism in early February as Gore came in dead last in the Iowa caucuses.

${ }^{20} \mathrm{Unfortunately}$ there are no reliable sources of information on contributions less than $\$ 200$, nor is it possible to ascertain precisely what percentage of the total number of contributions fell under this limit for each candidate. Based solely on the demographics of their constituencies, one would expect Jackson to have a larger percentage of small contributions than the other candidates. 
FIGURE 5

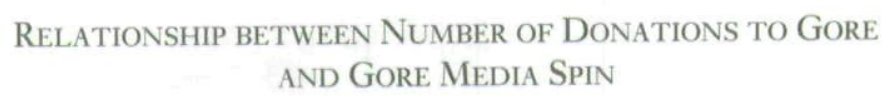

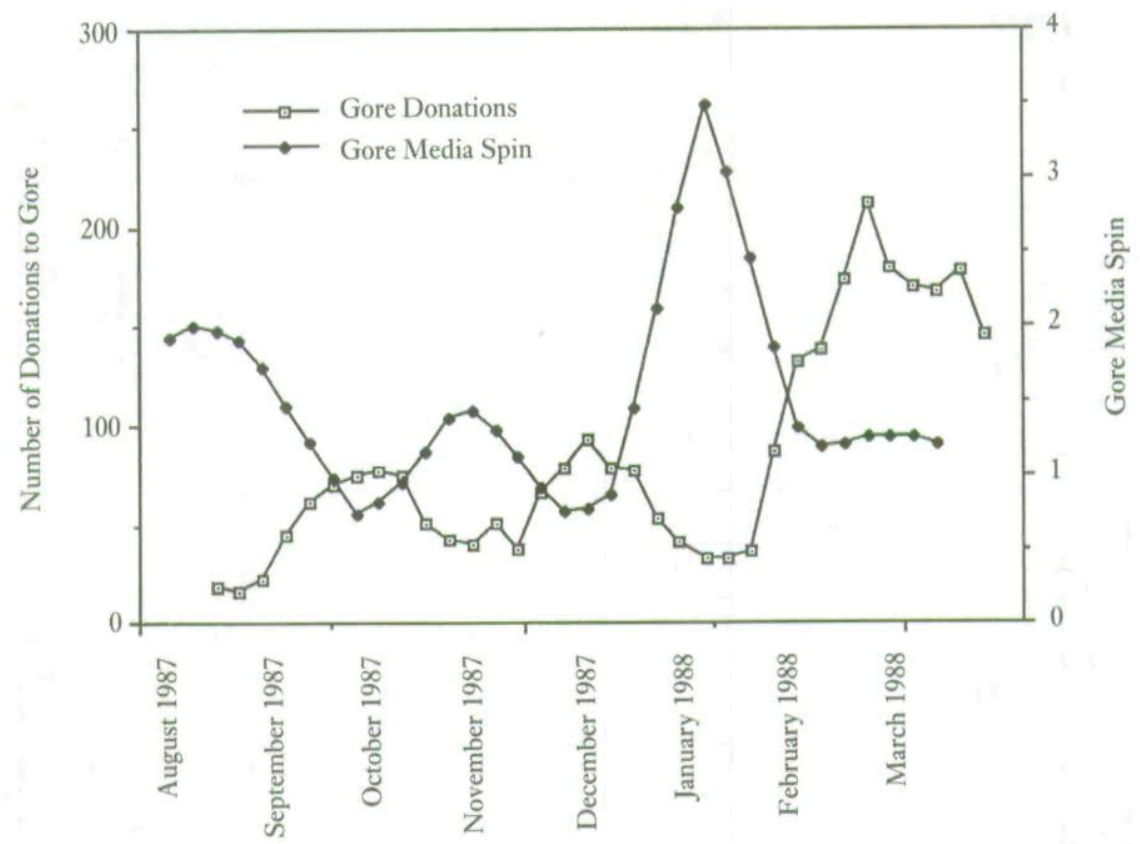

The coefficient for Jackson media spin is similar though slightly smaller, but this negative relationship is not as clear from the simple trend lines shown in figure 6. The peak in media spin in mid-September is followed by a small dip in donations in early October, and the peak in media spin in November is followed by a drop to an all-time low for donations in mid-December. But once the primary season begins, the pattern looks as if donations lead media spin rather than the other way around.

The three peaks in Jackson media spin coincide with some major turning points in the Jackson campaign. The September 1987 peak corresponds to Jackson's endorsement by Chicago Mayor Harold Washington. The increasingly negative spin in October corresponds to media coverage of Jackson's alleged anti-Semitism and accusations that he had been "coddled" by the media thus far in the campaign. Media spin climbed again in late October as Jackson was said to lead the Democratic pack according to a 27 October CBS/New York Times national poll. This same ranking was confirmed in a 29 November CBS/New York Times poll. The death of Harold Washington in late November and ensuing criticism surrounding Jackson's role in selecting a new mayor brought media portrayals of Jackson's viability down. By mid-December it reached an all-time low at about the same time 
FIGURE 6

RELATIONSHIP BETWEEN NUMBER OF DONATIONS TO JACKSON
AND JACKSON MEDIA SPIN

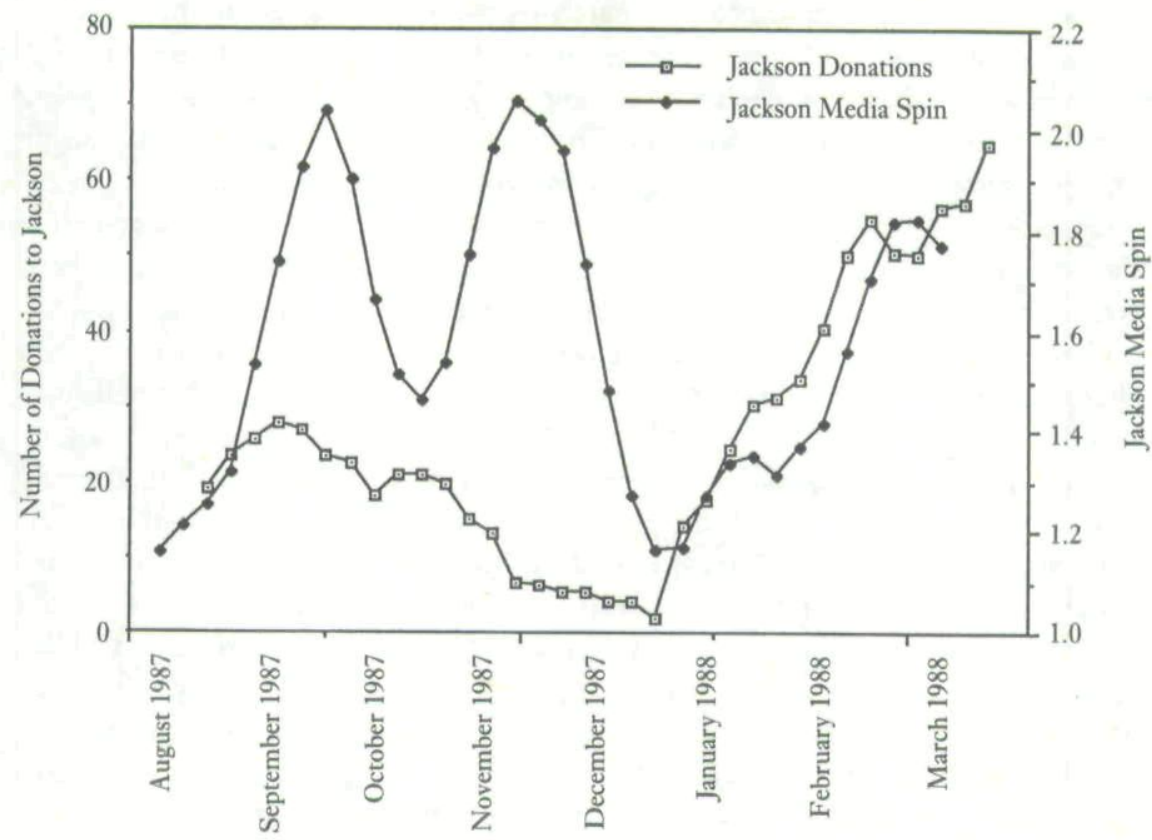

that the Alabama Democratic Conference cast doubts on Jackson's electability. Jackson's performance in the Iowa caucuses, the New Hampshire primary, and the Minnesota caucuses showed steady improvement with each contest and substantial improvements over his performance in 1984. This pattern is mirrored in the steadily more positive spin during this time period.

In addition to the interpretation suggested by loyalty-based contributing, there are several plausible rival interpretations of the relationships between media spin and contributions depicted in figure 5 and figure 6 . First, there is clearly no evidence in either case that positive media spin brings about increased contributions; only if one considered illogically long lag times such as two to three months would the peaks in media spin and contributions begin to suggest the pattern that characterizes hesitancy-based contributing. Second, although the idea that contributions might be driving media spin is plausible-particularly based on the data from Jackson's campaign-it seems highly unlikely when one considers the actual process that would have to transpire. Reporters use fund-raising success as a benchmark for judging candidate popularity, but reliable information on fund-raising progress is not available to reporters on a continuous, ongoing basis. The FEC has a small number of filing deadlines spaced many months apart and thus cannot 
possibly account for the continuous similarity of the trends. Moreover, candidates' own ongoing claims about fund-raising successes are treated by reporters with understandable suspicion and given little news play, precisely because they fear being used by candidates to instigate bandwagon-type phenomena (Arterton 1984).

Nonetheless, I attempted to eliminate this possibility by reexamining the relationships in table 3 and table 4 after removing from the sample of horse-race coverage all media coverage explicitly dealing with campaign finance. Results were virtually identical to the original ones. To the extent that coverage of fund-raising influences positive and negative spin, this relationship is indirect; fund-raising announcements may trigger more positive or negative spin in campaign stories on other topics, but the stories on campaign finance themselves are not driving these effects. Nor is horse-race spin merely a surrogate for the results of the latest publicopinion poll. Removing all poll-based stories from the sample of coverage does not change the relationships between horse-race spin and contributions, but polls may still be having indirect effects on the tone of coverage in stories on other topics.

More generally, there is yet another rival explanation that could challenge a causal interpretation of any of the relationships observed in table 3 and table 4 . As with most nonexperimental time-series data, it is always possible that some third variable not accounted for in the model is driving both decisions to donate and horse-race spin but at different lag times. For example, it is possible that policy statements or endorsements both increase positive media spin and increase the flow of donations independent of one another. In the case of events such as endorsements, it is doubtful that they could become known to large enough audiences without media coverage; once covered, they become part of horse-race spin and thus already are incorporated in the model. But coverage of things such as policy proposals would generally not show up in horse-race coverage and thus are unaccounted for in the model.

A final consideration in evaluating the extent to which these findings can be deemed causal relationships involves specification of the time lag. While variations in the equations increase the strength of some relationships and decrease others, the overall patterns remain robust unless the lag time is increased up to two full months, an unlikely lag time for a causal sequence of this kind.

In short, the causal inferences that can be drawn from these relationships are fairly strong relative to conclusions from cross-sectional aggregate and surveybased studies of contributor behavior. Time-series data make the direction of cause and effect unambiguous, and reverse causation is highly unlikely. The possibility remains that some third variable is driving both decisions to donate and horse-race spin, but it is difficult to envision something of this sort that has not been accounted for in the model, and that would produce these effects at lagged intervals.

Nonetheless, some caution should be exercised in generalizing from these findings to other contexts. Although these patterns do not appear to be specific to political parties, they might be specific to the 1988 presidential primaries or to these particular candidacies. However, the consistency of the pattern of findings across 
the eight candidates in 1988 suggests that they are likely to generalize fairly well to post-reform presidential primaries, though these same patterns may not obtain for congressional or general-election contests, or when media coverage de-emphasizes horse-race aspects of the process.

\section{DisCUSSION}

Current information about the political contribution activities of the mass public is largely limited to problematic survey-based self-report measures and cumulative data on entire election cycles. Although the FEC data on contributor behavior have their own shortcomings, this information makes it possible to use over-time variance in contributions to study the impact of factors other than stable personal attributes or characteristics of entire races or election cycles. The timing of decisions to contribute to primary campaigns is especially important since even a lot of money too late will be of little use to candidates, except in retiring campaign debts.

The results of this study suggest that giving money is a decision that often involves strategic considerations. To the extent that contributors are motivated by strategic considerations, mass media portrayals of the opinions of others may influence the decisions of potential contributors. Just as this consideration is sometimes important to people's vote choices, it is also important in determining the flow of money into campaigns.

However, the way in which perceptions of public support matter is probably more complex than popular wisdom might suggest. Just as there is ample evidence of both underdog and bandwagon reactions to representations of mass opinion, evidence to date suggests that both positive and negative horse-race spin may motivate contributors under different conditions. Although horse-race coverage is often decried, news about changes in candidate status may draw potential donors' attention to the campaign and act as an important motivating force fueling a campaign's progress.

The extent of strategic contributing documented in this particular election is probably a conservative estimate of what actually transpired. One reason to suspect that it represents a low-level baseline is that in an effort to insure that donations increased due to strategic motivations on the part of preexisting supporters, I controlled for changes in constituency size that may also be serving as strategic cues. Moreover, the conditions necessary to observe loyalty-or hesitancy-based strategic contributing in aggregate data are only present when the pool of potential donors is dominated by one or the other type of supporter. Simultaneous strategic contributing of both varieties may cancel one another out as a candidate's fortunes wax and wane over time.

From a normative perspective, these findings paint a fairly complimentary picture of primary activists. Just as not wanting to give money to a candidate who does not have much of a chance is a highly calculated basis on which to make a political decision, it is also well considered and logical to want to give money to a well-liked candidate when the candidate is in need and while the money still has a chance 
of helping him or her. In this sense the political reasoning observed in this study is of a highly evolved nature; horse-race coverage may be a shallow and lazy form of election coverage, but primary activists are anything but lazy in the uses they make of it.

Manuscript submitted 4 October 1993

Final manuscript received 19 January 1995

\section{REFERENCES}

Abramson, Paul R., John H. Aldrich, Phil Paolino, and David W. Rohde. 1992. “'Sophisticated' Voting in the 1988 Presidential Primaries." American Political Science Review 86:55-69.

Adams, William C., ed. 1983. Television Coverage of the 1980 Presidential Campaign. Norwood, NJ: Ablex.

Aldrich, John H. 1980. Before the Convention: Strategies and Choices in Presidential Nomination Campaigns. Chicago: University of Chicago Press.

Alexander, Herbert E., and Brian A. Haggerty. 1987. Financing the 1984 Election. Lexington: D.C. Heath.

Arterton, F. Christopher. 1984. Media Politics. Lexington, MA: D.C. Heath.

Bartels, Larry. 1988. Presidential Primaries and the Dynamics of Public Choice. Princeton, NJ: Princeton University Press.

Biersack, R., Paul S. Herrnson, L. Powell, Clyde Wilcox, and C. J. Brown Jr. 1992. "Seeking the Source of the Money Stream: The Flow of Individual Contributions in Federal Elections." Presented to the annual conference of the Midwest Political Science Association, Chicago.

Brady, Henry E., and Richard Johnston. 1987. "What's the Primary Message: Horse Race or Issue Journalism? In Media and Momentum, eds. G. R. Orren and N. W. Polsby. Chatham, NJ: Chatham House.

Broh, C. Anthony, 1977. "Horse-Race Journalism: Reporting the Polls in the 1976 Presidential Election." Public Opinion Quarterly 41:514-29.

Broh, C. Anthony. 1987. A Horse of a Different Color: Television's Treatment of Fesse Fackson's 1984 Presidential Campaign. Washington, DC: Joint Center for Political Studies.

Brown, C. W., R. B. Hedges, L. W. Powell. 1980. "Modes of Elite Political Participation: Contributors to the 1972 Presidential Candidates." American Fournal of Political Science 24:259-90.

Brown, C. W., L. Powell, and Clyde Wilcox. 1991. "Solicitors of Money for 1988 Presidential Nomination Candidates." Presented to the annual conference of the American Political Science Association, Washington, DC.

Brownstein, Ronald. 1987. "Raising Bucks for Bush." New York Times, 17 May, section 6, p. 42.

Ceci, Stephen J., and Edward L. Kain. 1982. "Jumping on the Bandwagon with the Underdog: The Impact of Attitude Polls on Polling Behavior." Public Opinion Quarterly 46:228-42.

Chaiken, Shelly, 1987. "The Heuristic Model of Persuasion." In Social Influence: The Ontario Symposium, vol. 5, eds. M. P. Zanna, J. M. Olson, and C. P. Herman. Hillsdale, NJ: L. Erlbaum.

Clark, P. B., and James Q. Wilson. 1961. "Incentive Systems: A Theory of Organization." Administrative Science Quarterly 6:138-46.

Cook, R. 1989. "The Nominating Process." In The Elections of 1988, ed. M. Nelson. Washington, DC: Congressional Quarterly Press.

Dionne, E. J. 1980. "Experts Find Polls Influence Activists." New York Times, 4 May, p. 26.

Fan, David P. 1988. Predictions of Public Opinion from the Mass Media. Westport, CT: Greenwood.

Fleitas, Daniel W. 1971. "Bandwagon and Underdog Effects in Minimal Information Elections." American Political Science Review 65:434-38. 
Gaskell, G. 1974. "Polls and the Voters." New Society 4:23-24.

Geer, John G. 1989. Nominating Presidents. New York: Greenwood.

Granberg, Don, and Edward Brent. 1983. "When Prophecy Bends: The Preference-Expectation Link in U.S. Presidential Elections, 1952-1980." Fournal of Personality and Social Psychology 45:477-91.

Hagen, Michael G. 1992. "Press Treatment of Presidential Front-runners." Presented to the annual meeting of the Midwest Political Science Association, Chicago, April.

Harvey, Andrew C. 1981. The Econometric Analyses of Time Series. New York: Wiley.

Haynes, A. A., and Gurian, P. 1992. "The Impact of Candidate Spending on Vote Outcomes in Presidential Prenomination Campaigns." Presented at the 1992 annual meeting of the Midwest Political Science Association, Chicago.

Heard, Alexander. 1960. The Costs of Democracy. Chapel Hill: University of North Carolina Press.

Henshel, Richard L., and W. Johnston. 1987. "The Emergence of Bandwagon Effects: A Theory." Sociological Quarterly 28:493-511.

Jacobson, Gary C., and Samuel Kernell. 1983. Strategy and Choice in Congressional Elections. New Haven: Yale University Press.

Jencks, Christopher. 1991. "Is Violent Crime Increasing?" The American Prospect Winter:98-109.

Johnston, John. 1972. Econometric Methods. 2d ed. New York: McGraw-Hill.

Johnston, Richard, Andre Blais, Henry E. Brady, and Jean Crete. 1990. "Do Campaigns Matter? The Dynamics of the 1988 Canadian Election." Presented at the annual meeting of the Midwest Political Science Association, Chicago, April.

Jones, Ruth S., and Warren E. Miller. 1985. "Financing Campaigns: Macro-level Innovations and Micro-level Response." Western Political Quarterly 38:187-210.

Judge, George G., William E. Griffiths, R. C. Hill, and T. C. Lee. 1980. The Theory and Practice of Econometrics. New York: Wiley.

Kaplowitz, Stan A., Edward L. Fink, Dave D'Alessio, and G. Blake Armstrong. 1983. "Anonymity, Strength of Attitude and the Influence of Public Opinion Polls." Human Communication Research $10: 5-25$.

Katz, Elihu, and Paul F. Lazarsfeld. 1955. Personal Influence. Glencoe: Free.

Kayden, Xandra. 1985. "Effects of the Present System of Campaign Financing on Special Interest Groups." In Before Nomination: Our Primary Problems, ed. George Grassmuck. Washington, DC: American Enterprise Institute.

Lengle, James I. 1981. Representation and Presidential Primaries: The Democratic Party in the Post-Reform Era. Westport, CT: Greenwood.

Marsh, Catherine. 1984. "Back on the Bandwagon: The Effect of Opinion Polls on Public Opinion." British Fournal of Political Science 15:51-74.

Marshall, Thomas R. 1983. "The News Verdict and Public Opinion during the Primaries." In Television Coverage of the 1980 Presidential Campaign, ed. W. C. Adams. Norwood, NJ: Ablex.

McBurnett, Michael. 1991. "The Dynamics of Voter Preference in Primary Campaigns." Presented to the annual conference of the Midwest Political Science Association, Chicago.

Mutz, Diana C. 1992. "Impersonal Influence: Effects of Representations of Public Opinion on Political Attitudes." Political Behavior 14:89-122.

Mutz, Diana C. 1995. "Media, Momentum and Money: Horse Race Spin in the 1988 Republican Primaries." In Polls and the News Media, eds. Paul J. Lavrakas, Michael W. Traugott, and Peter V. Miller. Boulder, CO: Westview Press.

Nacos, B. L., Robert Y. Shapiro, J. T. Young, David P. Fan, T. Kjellstrand, and C. McCaa. 1991. "Content Analysis of News Reports: Comparing Human Coding and a Computer-Assisted Method." Communication 12:111-28.

Orren, Gary R. 1985. "The Nomination Process: Vicissitudes of Candidate Selection." In The Elections of 1984, ed. Michael Nelson. Washington, DC: Congressional Quarterly Press.

Overacker, Louise. 1932. Money in Elections. New York: Macmillan.

Patterson, Thomas E. 1980. The Mass Media Election. New York: Praeger. 
Petty, Richard E., and John T. Cacioppo. 1979. "Issue Involvement Can Increase or Decrease Persuasion by Enhancing Message-relevant Cognitive Responses." Fournal of Personality and Social Psychology 37: 1915-26.

Petty, Richard E., and John T. Cacioppo. 1981. Attitudes and Persuasion: Classic and Contemporary Approaches. Dubuque: William C. Brown.

Polsby, Nelson W. 1983. Consequences of Party Reform. New York: Oxford University Press.

Pomper, Gerald M. 1989. "The Presidential Nominations." In The Election of 1988: Reports and Interpretations, ed. Gerald Pomper. Chatham, NJ: Chatham House.

Popkin, Samuel L. 1991. The Reasoning Voter. Chicago: University of Chicago Press.

Price, Vincent. 1989. "Social Identification and Public Opinion: Effects of Communicating Group Conflict." Public Opinion Quarterly 53:197-224.

Robinson, Michael J., and Maura Clancey. 1985. "Teflon Politics." In The Mass Media in Campaign '84, eds. Michael J. Robinson and Austin Ranney. Washington, DC: American Enterprise Institute.

Robinson, W. S. 1950. "Ecological Correlations and the Behavior of Individuals." American Sociological Review: 351-57.

Sigelman, Lee. 1989. "The 1988 Presidential Nomination: Whatever Happened to Momentum?" PS: Political Science and Politics 22:35-39. Washington, DC: American Political Science Association.

Sorauf, Frank J. 1988. Money in American Elections. Washington, DC: Congressional Quarterly Press. Stone, Walter J., Lonna R. Atkeson, and Sean Q. Kelly. 1991. "Candidate Choice on Super Tuesday: An Expected Utility Approach." Presented at the annual conference of the American Political Science Association, Washington, DC, September.

Traugott, Michael W. 1985. "The Media and the Nominating Process." In Before Nomination: Our Primary Problems, ed. George Grassmuck. Washington, DC: American Enterprise Institute.

Verba, Sidney, and Norman H. Nie. 1972. Participation in America. Chicago: University of Chicago Press.

Werth, B. 1988, "The Incredible Rolodex." New England Monthly, July.

Wilson, James Q. 1973. Political Organizations. New York: Basic Books.

Diana C. Mutz is associate professor of political science, journalism, and mass communication, University of Wisconsin, Madison, WI 53706. 
Copyright of Journal of Politics is the property of Cambridge University Press / UK and its content may not be copied or emailed to multiple sites or posted to a listserv without the copyright holder's express written permission. However, users may print, download, or email articles for individual use. 